\title{
LAS MULTAS COERCITIVAS POR INCUMPLIMIENTO DE LAS DECISIONES DEL TRIBUNAL DE JUSTICIA DE LA UNIÓN EUROPEA EN MATERIA MEDIOAMBIENTAL
}

\section{PENALTY PAYMENTS FOR LACK OF ENFORCEMENT OF DECISIONS OF THE COURT OF JUSTICE OF THE EUROPEAN UNION IN ENVIRONMENTAL MATTERS}

\author{
ANA GASCÓN MARCÉN \\ Profesora Contratada Doctora Interina \\ Universidad de Zaragoza \\ angascon@unizar.es
}

Fecha de recepción: 8 de junio de 2020 / Fecha de aceptación: 3 de julio de 2020

RESUMEN: En este trabajo, se analizan las repercusiones que puede tener para los Estados el incumplimiento de las decisiones del Tribunal de Justicia de la Unión Europea en materia medioambiental. Se examina el mecanismo del artículo 260 del Tratado de Funcionamiento de la Unión Europea, es decir, las sanciones (multas coercitivas y sumas a tanto alzado) que se dictan cuando no se respeta una sentencia de un recurso de incumplimiento. Se estudia también la posibilidad de imponer multas coercitivas cuando un Estado no acata las medidas provisionales dictadas por el Tribunal, como ocurrió por primera vez en el caso Białowieża.

RESUM: En aquest treball, s'analitzen les repercussions que pot tenir per als Estats l'incompliment dels decisions del Tribunal de Justícia de la Unió Europea en matèria mediambiental. S'examina el mecanisme de l'article 260 del Tractat de Funcionament de la Unió Europea, és a dir, les sancions (multes coercitives i sumes a preu fet) que es dicten quan no es respecta una sentència d'un recurs d'incompliment. S'estudia també la possibilitat d'imposar multes coercitives quan un Estat no acata les mesures provisionals dictades pel Tribunal, com va passar per primera vegada en el cas Białowieża. 
ABSTRACT: This paper analyzes the repercussions for the States of the nonenforcement of the decisions of the Court of Justice of the European Union in environmental matters. The mechanism of article 260 of the Treaty on the Functioning of the European Union is examined, that is, the sanctions (penalty payments and lump sums) that can be dictated when a judgment of an infringement proceeding is not respected. The possibility of imposing periodic penalty payments when a State does not comply with interim measures ordered by the Court (as it happened for the first time in the Białowieża case) is also studied.

PALABRAS CLAVE: Tribunal de Justicia de la Unión EuropeaIncumplimiento-Medidas provisionales-Multa coercitiva-Sumas a tanto alzado—Artículo 260 TFUE—Artículo 279 TFUE—Caso Białowieża

PARAULES CLAU: Tribunal de Justícia de la Unió Europea-IncomplimentMesures provisionals-Multa coercitiva-Sumes a preu fet-Article 260 TFUEArticle 279 TFUE-Cas Białowieża

KEYWORDS: Court of Justice of the European Union-Lack of enforcementProvisional measures-Penalty payment-Lump sum-Article 260 TFEUArticle 279 TFEU—Case Białowieża

SUMARIO: I. Introducción. II. Medidas en caso de incumplimiento de una sentencia del Tribunal de Justicia de la Unión Europea: artículo 260 TFUE III. Medidas en caso de incumplimiento de las medidas provisionales del Tribunal de Justicia de la Unión Europea 1. Las medidas provisionales en materia medioambiental 2. Las multas coercitivas por incumplimiento de las medidas provisionales en el caso "Białowieża" IV. Conclusiones V. Bibliografía

\section{INTRODUCCIÓN}

El artículo 3 del Tratado de la Unión Europea (TUE) fija los objetivos de ésta y dispone que la Unión Europea (UE) obrará en pro del desarrollo sostenible de Europa basado en un nivel elevado de protección y mejora de la calidad del medio ambiente. El título XX del Tratado de Funcionamiento de la Unión Europea (TFUE) se consagra al medio ambiente, desarrolla los principios de esta política 
y describe como el Parlamento Europeo y el Consejo, con arreglo al procedimiento legislativo ordinario, decidirán las acciones que deba emprender la UE para la realización de dichos objetivos. Eso se ha traducido en cientos de normas medioambientales de la UE que han conllevado una mayor exigencia en este ámbito en países como España.

A pesar de que se trata de una competencia compartida conforme al artículo 4 TFUE, se calcula que la legislación de la UE se encuentra detrás del $80 \%$ de la legislación medioambiental nacional, y es responsable de importantes mejoras en la calidad del aire y del agua, y la eliminación de contaminantes como el plomo en la gasolina. ${ }^{1}$ Las políticas medioambientales van a ganar si cabe más peso durante los próximos años, porque son una de las actuales prioridades de la Comisión Europea con el Pacto Verde Europeo, una nueva estrategia de crecimiento llamada a transformar la UE. ${ }^{2}$

En muchas ocasiones, se pone énfasis en las reformas legislativas necesarias para proteger el medio ambiente, y está claro que a la UE le queda mucho por hacer en ese sentido, pero también es importante fijarse en la puesta en práctica de la legislación ya existente. La UE lleva varios años intentando avanzar en la mejora de la aplicación de su legislación en general ${ }^{3}$ y la medioambiental en particular. El primer paquete de revisión de la aplicación de la normativa medioambiental se adoptó en $2017^{4}$ y el segundo en 2019.5 Sin embargo, según

\footnotetext{
1 DG Environment, Management Plan 2013, Ref. Ares(2013)41606, p. 37. Disponible en: $<$ https://ec.europa.eu/dgs/environment/pdf/management plan 2013.pdf> [Última consulta, 5 de mayo de 2020].

2 Comunicación de la Comisión al Parlamento Europeo, al Consejo Europeo, al Consejo, al Comité Económico y Social Europeo y al Comité de las Regiones: El Pacto Verde Europeo, COM/2019/640 final. Disponible en: <https://eur-lex.europa.eu/legalcontent/ES/TXT/?uri=CELEX:52019DC0640> [Última consulta, 5 de mayo de 2020].

${ }^{3}$ Comunicación de la Comisión - Derecho de la UE: mejores resultados gracias a una mejor aplicación (2017/C 18/02). Disponible en: <https://eur-lex.europa.eu/legalcontent/ES/ALL/?uri=CELEX\%3A52017XC0119\%2801\%29> [Última consulta, 5 de mayo de 2020].

${ }^{4}$ Comunicación de la Comisión al Parlamento Europeo, al Consejo, al Comité Económico y Social Europeo y al Comité de las Regiones "Revisión de la aplicación de la normativa medioambiental de la UE: problemas comunes y cómo combinar esfuerzos para obtener mejores resultados, $\operatorname{COM}(2017) \quad 63$ final. Disponible en: <https://eur-lex.europa.eu/legalcontent/ES/ALL/?uri=COM\%3A2017\%3A63\%3AFIN> [Última consulta, 5 de mayo de 2020].

${ }^{5}$ Comunicación de la Comisión al Parlamento Europeo, al Consejo, al Comité Económico y Social Europeo y al Comité de las Regiones "Revisión de la aplicación de la normativa medioambiental 2019: Una Europa que protege a sus ciudadanos y mejora su calidad de vida", $\operatorname{COM(2019)~} 149$ final. Disponible en: <https://eur-lex.europa.eu/legal-content/ES/TXT/?uri=COM:2019:0149:FIN> [Última consulta, 5 de mayo de 2020].
} 
algunos autores, ninguna norma europea se viola tanto como las directivas medioambientales. ${ }^{6}$

Existen relevantes diferencias entre los objetivos marcados por la legislación de la UE y los conseguidos por los Estados, es lo que se conoce como implementation gap o deficiencias en la aplicación en el ámbito medioambiental. ${ }^{7}$ Además, se necesitan esfuerzos significativos en la implementación de políticas climáticas y ambientales para que la UE avance de manera efectiva hacia sus compromisos internacionales. El Institute for European Environmental Policy en sus evaluaciones recientes de las políticas ambientales emblemáticas de la UE, como la Política Agrícola Común, las Directivas de Aves $^{8}$ y Hábitats, ${ }^{9}$ o la Directiva Marco de Aguas, ${ }^{10}$ ha puesto de manifiesto una brecha de implementación significativa que socava las ambiciones ambientales de la UE. ${ }^{11}$ Se calcula que las deficiencias en la aplicación de la normativa ambiental de la UE cuestan a los europeos alrededor de 55000 millones de euros al año. ${ }^{12}$

La Comisión cuenta con múltiples mecanismos para ayudar a los Estados a cumplir con la normativa, ${ }^{13}$ pero en ocasiones éstos se muestran renuentes y se ve obligada a actuar como "guardiana de los tratados". ${ }^{14}$ Ante estas situaciones,

\footnotetext{
6 Tanja A. Börzel, Environmental Leaders and Laggards in Europe. Why There is (Not) a 'Southern Problem', Routledge, Londres, 2003.

7 Véase Andrew Jordan "The Implementation of EU Environmental Policy; A Policy Problem without a Political Solution?", en Environment and Planning: Government and Policy, vol. 17, núm. 1, pp. 69-90. Disponible en: <https://doi.org/10.1068/c170069> [Última consulta, 5 de mayo de 2020]; y Tanja A. Börzel y Aron Buzogány, "Compliance with EU environmental law. The iceberg is melting", en Environmental Politics, vol. 28, núm. 2, 2019, pp. 315-34. Disponible en: $<$ https://doi.org/10.1080/09644016.2019.1549772> [Última consulta, 5 de mayo de 2020].

8 Directiva 2009/147/CE del Parlamento Europeo y del Consejo, de 30 de noviembre de 2009, relativa a la conservación de las aves silvestres, DOUE L 20, 26.1.2010, pp. 7-25.

${ }^{9}$ Directiva 92/43/CEE del Consejo, de 21 de mayo de 1992, relativa a la conservación de los hábitats naturales y de la fauna y flora silvestres, DOUE L 206 de 22.7.1992, pp. 7-50.

${ }^{10}$ Directiva 2000/60/CE del Parlamento Europeo y del Consejo, de 23 de octubre de 2000, por la que se establece un marco comunitario de actuación en el ámbito de la política de aguas, DOUE L 327, 22.12.2000, pp. 1-73.

${ }^{11}$ Véase Institute for European Environmental Policy, Closing the gap: implementing European environmental policies, 2019.

$<$ https://ieep.eu/uploads/articles/attachments/a41d4af7-fb05-4a7f-8ddfDisponible en: 8d6b077f828d/Closing\%20the\%20gap\%20-\%20final.pdf?v=63727460550 > [Última consulta, 5 de mayo de 2020].

12 COWI y Eunomia, Study: The costs of not implementing EU environmental law, Comisión Europea, 2019.2 Disponible en: $<$ https://ec.europa.eu/environment/eir/pdf/study costs not implementing env law.pdf> [Última consulta, 5 de mayo de 2020].

${ }^{13}$ Por ejemplo, la Red europea para la aplicación y el cumplimiento de la legislación en materia de medio ambiente (IMPEL).

${ }^{14}$ Artículo 17 TUE.
} 
la Comisión Europea puede comenzar un procedimiento pre-contencioso de infracción a través de una carta de emplazamiento dirigida al Estado que sospeche que está incumpliendo. ${ }^{15}$ Se inicia así un diálogo con el Estado para investigar si efectivamente se da un incumplimiento y permitirle, en su caso, que tome las medidas oportunas.

El cumplimiento del Derecho de la UE puede tener un efecto considerable en un país y algunos Estados lo retrasan, a pesar de su deber de cooperación leal. A esto se suma que la política medioambiental de la UE se considera generalmente como un campo muy disputado y particularmente costoso en su implementación para los Estados miembros, a veces más de lo esperado en el momento de su adopción. ${ }^{16}$

Además, la política ambiental suele requerir la colaboración de un gran número de actores regionales o locales lo que puede hacer más difícil su cumplimiento. España es un ejemplo, porque muchas de las competencias en esta materia corresponden a las Comunidades Autónomas o incluso a los ayuntamientos.

De las 3850 denuncias por incumplimiento que recibió la Comisión en 2018, 339 tenían que ver con el medio ambiente, es decir, un 9\%. De éstas, la mayoría estaban relacionadas con componentes químicos, evaluación de impacto ambiental y protección de la naturaleza. ${ }^{17}$ España es el Estado miembro contra el que más denuncias se interpusieron y la tercera razón más común era el incumplimiento de las normas medioambientales, con 57 denuncias de un total de 486 , es decir, un $12 \%$. $^{18}$

\footnotetext{
${ }^{15}$ En 2018, la Comisión inició 73 procedimientos de infracción en materia medioambiental. Se trataba de la segunda política con más después de la de mercados de capitales y tenían que ver fundamentalmente con calidad del aire, gestión de residuos y protección y gestión de las aguas. Comisión Europea, Monitoring the Application of Union Law 2018 Annual Report. Part I: general statistical overview, 2019, p. 19. Disponible en: <https://ec.europa.eu/info/sites/info/files/report2018-commission-staff-working-document-monitoring-application-eu-law-general-statisticaloverview-part1 0.pdf>[Última consulta, 5 de mayo de 2020].

${ }^{16}$ Gerda Falkner "A causal loop? The Commission's new enforcement approach in the context of non-compliance with EU law even after CJEU judgments", en Journal of European Integration, vol. 40, núm. 6, 2018, pp. 769-784, p. 779. Disponible en: $<$ https://www.tandfonline.com/doi/full/10.1080/07036337.2018.1500565> [Última consulta, 5 de mayo de 2020].

${ }^{17}$ Comisión Europea, Monitoring the Application of Union Law 2018 Annual Report. Part II: policy areas, 2019, p. 27. Disponible en: <https://ec.europa.eu/info/sites/info/files/report-2018commission-staff-working-document-monitoring-application-eu-law-policy-areas-part2.pdf> [Última consulta, 5 de mayo de 2020].

${ }^{18}$ Comisión Europea, Monitoring the Application of Union Law 2018 Annual Report. Part I: general statistical overview, 2019, p. 12. Disponible en: <https://ec.europa.eu/info/sites/info/files/report-
} 
La Comisión no dispone de los recursos necesarios para una supervisión general y realmente amplia de los Estados en esta materia. ${ }^{19}$ Puede iniciar procedimientos de infracción de oficio, pero sólo lo hace cuando detecta problemas estructurales. En 2018, esto ocurrió en casos relacionados con la transposición incorrecta de la Directiva sobre la protección de los animales utilizados para fines científicos; ${ }^{20}$ la protección inadecuada de especies y hábitats; el incumplimiento de las normas de la UE sobre calidad del aire; el tratamiento inadecuado de las aguas residuales urbanas; la protección insuficiente de las aguas contra la contaminación causada por nitratos procedentes de la agricultura; el incumplimiento de la Directiva marco de aguas, de la Directiva de inundaciones ${ }^{21}$ y de las disposiciones sobre residuos. ${ }^{22}$

La mayoría de los procedimientos de infracción se cierran bien porque después de la investigación se considera que no había un incumplimiento o más frecuentemente porque el Estado toma las medidas necesarias. No obstante, una vez enviado el dictamen motivado ${ }^{23}$ y pasado el período de observaciones, si la Comisión considera que el Estado efectivamente falta a sus obligaciones dimanantes del Derecho de la UE, puede interponer un recurso de incumplimiento ante el Tribunal de Justicia de la Unión Europea (TJUE), conforme al artículo 258 TFUE. El Tribunal ha tenido un papel muy relevante en

2018-commission-staff-working-document-monitoring-application-eu-law-general-statisticaloverview-part1 0. pdf> [Última consulta, 5 de mayo de 2020].

${ }^{19}$ Véase María Isabel Rodríguez Valero, Administrative procedure in environment files linked with Article 258 TFEU proceedings: a lawyer's perspective, Parlamento Europeo, 2010. Disponible en: $\quad<$ https://www.europarl.europa.eu/RegData/etudes/note/join/2011/432753/IPOLJURI NT(2011)432753 EN.pdf> [Última consulta, 5 de mayo de 2020]; y Sibylle Grohs, "Article 258/260 TFEU Infringement Procedures: The Commission Perspective in Environmental Cases", en Compliance and the Enforcement of EU Law, Marise Cremona (ed.), Oxford University Press, 2012, pp. 57-73.

20 Directiva 2010/63/UE del Parlamento Europeo y del Consejo, de 22 de septiembre de 2010, relativa a la protección de los animales utilizados para fines científicos, DOUE L 276, 20.10.2010, pp. 33-79.

${ }_{21}$ Directiva 2007/60/CE del Parlamento Europeo y del Consejo, de 23 de octubre de 2007, relativa a la evaluación y gestión de los riesgos de inundación, DOUE L 288, 6.11.2007, pp. 2734.

${ }^{22}$ Comisión Europea, Monitoring the Application of Union Law 2018 Annual Report. Part II: policy areas, 2019, p. 29. Disponible en: <https://ec.europa.eu/info/sites/info/files/report-2018commission-staff-working-document-monitoring-application-eu-law-policy-areas-part2.pdf>

[Última consulta, 5 de mayo de 2020].

${ }^{23}$ En 2018, la Comisión notificó 30 dictámenes motivados en materia medioambiental. Se trataba de la segunda política con más después de la de mercados de capitales. Comisión Europea, Monitoring the Application of Union Law 2018 Annual Report. Part I: general statistical overview, 2019, p. 19. Disponible en: <https://ec.europa.eu/info/sites/info/files/report-2018-commissionstaff-working-document-monitoring-application-eu-law-general-statistical-overview-part1 0 .pdf> [Última consulta, 5 de mayo de 2020]. 
la supervisión del cumplimiento de las normas medioambientales por parte de los Estados miembros. ${ }^{24}$

En este trabajo se analizará qué ocurre cuando los Estados no cumplen las decisiones del TJUE en materia de medio ambiente, ya sea porque no respetan una de sus sentencias (apartado II) o las medias provisionales que éste impone (apartado III).

\section{MEDIDAS EN CASO DE INCUMPLIMIENTO DE UNA SENTENCIA DEL TRIBUNAL DE JUSTICIA DE LA UNIÓN EUROPEA: ARTÍCULO 260 TFUE}

El incumplimiento de las sentencias del Tribunal de Justicia puede tener un efecto pernicioso sobre el mercado interior, resultar discriminatorio para los ciudadanos europeos o tener un impacto muy negativo sobre el medio ambiente. No obstante, muchos Estados retrasaban la toma de las medidas pertinentes por su elevado coste político, económico o social. Por lo que se tornó necesario crear mecanismos coercitivos para que los Estados se vieran forzados a acatar las sentencias y actuar en consecuencia, aunque en un principio los Tratados constitutivos de las Comunidades Europeas no hubieran articulado ningún instrumento al respecto.

El Tratado de Maastricht, que entró en vigor en 1993, creó la posibilidad de que si el Estado afectado no toma las medidas que entrañe la ejecución de la sentencia del Tribunal en el plazo establecido por la Comisión, ésta podrá someter el asunto al Tribunal de Justicia. Se sigue tratando de un recurso de incumplimiento, siendo la primera sentencia lo que se incumple en este caso. Este recurso ha sido también denominado de ejecución o inejecución, en francés, manquement sur manquement, y, en inglés, twofold failure.

En este segundo recurso, la Comisión indicaría el importe que considerase apropiado a las circunstancias para la suma a tanto alzado o la multa coercitiva que debería ser pagada por el Estado afectado. Si el Tribunal declara que el

\footnotetext{
${ }^{24}$ En 2006, se calculaba que el Tribunal había adoptado más de 700 sentencias relacionadas con más de 50 actos legislativos comunitarios diferentes que regulaban directa o indirectamente las cuestiones medioambientales, así como medidas nacionales en la materia, principios generales y disposiciones del Tratado. Véase Francis Jacobs, "The role of the European Court of Justice in the protection of the environment", en Journal of Environmental Law, vol. 18, núm. 2, 2006, pp. 185-205, p. 185. doi: 10.1093/jel/eql012 [Última consulta, 5 de mayo de 2020].
} 
Estado ha incumplido su sentencia, podría así imponerle el pago de una suma a tanto alzado o de una multa coercitiva. Esto se tornaría en elevados costes para el Estado incumplidor que se vería fuertemente motivado a cumplir en el menor espacio de tiempo, y se suponía que tendría un efecto disuasorio frente a futuros incumplimientos.

Esta posibilidad aparece en el artículo 260 TFUE actualmente vigente. El Tratado de Lisboa suprimió la etapa pre-contenciosa del dictamen motivado y especificó que, cuando el incumplimiento proviniera de que el Estado no hubiera informado sobre las medidas de transposición de una directiva, la Comisión podría acudir directamente a este mecanismo para que se fijara una multa sin haber una sentencia previa condenatoria (art 260.3). ${ }^{25}$

La primera sentencia del TJUE en un recurso por doble incumplimiento tardó en llegar y no se daría hasta el año $2000,{ }^{26}$ cuando se condenó a Grecia por incumplir una sentencia que se había dictado a su vez en $1992^{27}$ contra ese Estado y que traía causa en una queja presentada a la Comisión en 1987 por la que se denunciaba el vertido incontrolado de residuos por parte de varios municipios del departamento de La Canea (Creta) en el torrente Kouroupitos, a 200 metros del mar. ${ }^{28}$

El Tribunal declaró que Grecia, a pesar de ser impelida a ello en su primera sentencia, no había adoptado las medidas necesarias para garantizar que en la región de La Canea los residuos fueran eliminados sin poner en peligro la salud humana y sin perjudicar al medio ambiente. Por ello, el Tribunal condenó a Grecia a pagar a la Comisión una multa coercitiva de $20000 €$ por día de retraso

\footnotetext{
${ }^{25}$ Esta posibilidad fue ejercida por primera vez por la Comisión en el caso que daría lugar a la STJUE de 8 de julio de 2019, Comisión Europea c. Reino de Bélgica, asunto C-543/17, ECLI:EU:C:2019:573.

Véase Steve Peers "Sanctions for Infringement of EU Law after the Treaty of Lisbon", en European Public Law, vol. 18 (2012), pp. 33-64.

${ }^{26}$ STJCE de 4 de julio de 2000, Comisión de las Comunidades Europeas c. República Helénica, asunto C-387/97, ECLI:EU:C:2000:356.

${ }^{27}$ STJCE de 7 de abril de 1992, Comisión de las Comunidades Europeas c. República Helénica, asunto C-45/91, ECLI:EU:C:1992:164.

${ }^{28}$ Véase Paz Andrés Sáenz de Santamaría, "Primera multa coercitiva a un estado miembro por inejecución de sentencia. (Comentario a la STJCE de 4 de julio de 2000, Comisión c. Grecia)", en Revista de Derecho Comunitario Europeo, no 8, 2000, pp. 493-518; y Carlos Moreiro González, "A propósito de la Sentencia del Tribunal de Justicia de 4 de julio de 2000 en el asunto C-387/97, Comisión CE, apoyada por Reino Unido contra Grecia”, en Gaceta Jurídica, no 208, 2000, pp. 87-95.
} 
en la adopción de las medidas necesarias. Grecia tuvo que pagar hasta marzo de 2001 cuando los residuos pasaron a tratarse en una instalación adecuada. Esto supuso un desembolso total de 5,4 millones de euros en concepto de multa coercitiva. $^{29}$

Como puede verse se trataba de un asunto en materia medioambiental y que había persistido durante un largo período de tiempo con consecuencias muy perniciosas para la naturaleza.

La siguiente sentencia ${ }^{30}$ condenó a España en 2005 por seguir, a pesar de una anterior sentencia condenatoria, ${ }^{31}$ incumpliendo las obligaciones impuestas relativas a la calidad de las aguas de baño. El Tribunal condenó a España a una multa coercitiva de $624150 €$ al año por cada punto porcentual de zonas de baño en las aguas interiores españolas cuya no conformidad con los valores límite fijados en virtud de la Directiva de calidad de las aguas de baño quedará demostrada respecto del año en cuestión, a partir del momento en que se evalúe la calidad de las aguas de baño correspondiente a la primera temporada de baño siguiente al pronunciamiento de la sentencia. Como se puede observar, esta sentencia también traía causa en un largo incumplimiento en materia ambiental. España cumplió la sentencia a finales de ese mismo año ${ }^{32}$ y la Comisión decidió no exigirle el pago de la multa coercitiva. ${ }^{33}$

Al principio la Comisión y el Tribunal se decantaron por multas coercitivas por ser el instrumento más efectivo y porque de una interpretación literal del Tratado

\footnotetext{
${ }^{29}$ Comisión Europea, Decimonoveno Informe Anual sobre el control de la aplicación del Derecho comunitario (2001), $\operatorname{COM}(2002) 324$ final, p. 55. Disponible en: $<$ https://ec.europa.eu/transparency/regdoc/rep/1/2002/ES/1-2002-324-ES-F1-1.Pdf> [Última consulta, 5 de mayo de 2020].

30 STJCE de 25 de noviembre de 2003, Comisión de las Comunidades Europeas c. Reino de España, asunto C-278/01, ECLI:EU:C:2003:635. Véase Teresa Fajardo del Castillo "Primera multa coercitiva a España en aplicación del procedimiento del artículo 228.2 del Tratado CE: comentario a la sentencia del TJCE de 25 de noviembre de 2003, Comisión c. España, as. C278/01", en Revista General de Derecho Europeo, №. 4, 2004.

${ }^{31}$ STJCE de 12 de febrero de 1998, Comisión de las Comunidades Europeas c. Reino de España, asunto C-92/96, ECLI:EU:C:1998:53.

${ }^{32}$ Commission Staff Working Document. Annex to the 23rd Annual Report from the Commission on monitoring the application of Community Law (2005) \{com(2006) 416 final\}. Situation in the different sectors, SEC(2006) 999. Disponible en: $<$ https://ec.europa.eu/info/sites/info/files/file import/Situation sectors 2005\%5BSEC\%282006\% 29999\%5D en 0.pdf> [Última consulta, 5 de mayo de 2020].

${ }^{33}$ Ian Kilbey, "Financial penalties under Article 228(2) EC: Excessive complexity?", en Common Market Law Review, vol. 44, núm. 3, 2007, pp. 743-759, p. 749. Disponible en: $<$ https://kluwerlawonline.com/JournalArticle/Common\%20Market\%20Law\%20Review/44.3/5253 $>$ [Última consulta, 5 de mayo de 2020].
} 
parecía que se trataba de penas alternativas, es decir, que debía imponerse una o la otra. Sin embargo, el Tribunal (a propuesta del Abogado General) ${ }^{34}$ decidió modificar esta aproximación y en 2005 declaró que la aplicación de una u otra de estas medidas dependía de la idoneidad de cada una de ellas para cumplir el objetivo perseguido en función de las circunstancias del caso concreto. ${ }^{35}$

La imposición de una multa coercitiva resultaba especialmente adaptada para inducir a un Estado miembro a poner fin lo antes posible a un incumplimiento que, de no existir dicha medida, tendría tendencia a persistir. Mientras que la imposición del pago de una suma a tanto alzado descansaría en la apreciación de las consecuencias del incumplimiento de las obligaciones del Estado afectado sobre los intereses privados y públicos, en especial cuando el incumplimiento se hubiera mantenido largo tiempo después de la sentencia que inicialmente lo declaró.

Así, el Tribunal impuso ambas cumulativamente a Francia que no había establecido un control que garantizase el respeto de las medidas técnicas comunitarias para la conservación de los recursos pesqueros, a pesar de que la Comisión sólo había pedido una multa coercitiva. El Tribunal condenó a Francia a pagar una multa de $57761250 €$ por cada período de seis meses, a contar desde la fecha de la segunda sentencia, al final del cual aún no se hubiera ejecutado plenamente la primera sentencia del caso inicial, y a una suma a tanto alzado de 20 millones de euros por el período de incumplimiento desde la primera hasta la segunda sentencia.

\footnotetext{
${ }^{34}$ Conclusiones del Abogado General Sr. L.A. Geelhoed, presentadas el 29 de abril de 2004, y Conclusiones del Abogado General Sr. L.A. Geelhoed, presentadas el 18 de noviembre de 2004, ambas en el caso C-304/02. Véase Anne Rigaux, « Manquement sur manquement: propositions inédites de l'Avocat général sur les conséquences financières potentielles des manquements persistants et structurels », en Europe 2004 Juin Chron, núm. 4, pp. 4-5; y Laure Clément-Wilz, « Une nouvelle interprétation de l'article 228-2 CE favorisée par le dialogue entre la Cour et son Avocat général », en Cahiers de droit européen, 2005, pp. 725-748.

${ }^{35}$ STJCE de 12 de julio de 2005, Comisión de las Comunidades Europeas c. Francia, asunto C304/02, ECLI:EU:C:2005:444. Véase Marta Sobrido-Prieto, "Primera condena al pago simultáneo de una multa coercitiva y de una suma a tanto alzado por inejecución de sentencia: comentario a la Sentencia del Tribunal de Justicia de las Comunidades Europeas de 12 de julio de 2005, C304/02, Comisión / Francia", en Revista General de Derecho Europeo, №. 9, 2006; y Pål Wennerås, "A new dawn for Commission enforcement under Articles 226 and 228 EC: General and persistent (gap) infringements, lump sums and penalty payments", en Common Market Law Review, vol. 43, núm. 1, 2006, pp. 31-62. Disponible en: $<$ https://kluwerlawonline.com/JournalArticle/Common\%20Market\%20Law\%20Review/43.1/4072 $>$ [Última consulta, 5 de mayo de 2020].
} 
Francia cumplió con la sentencia en 2006, no obstante, cuando la Comisión le exigió el pago de los $57761250 €$ a través de la Decisión C(2006) 659 final, de 1 de marzo de 2006, interpuso un recurso contra la misma en el que pedía su anulación o subsidiariamente su reducción que, sin embargo, fue desestimado por el Tribunal General. ${ }^{36}$ Entre otros argumentos, Francia consideraba que la Comisión no tenía competencia para exigir el pago de la multa lo que no fue evidentemente estimado por el Tribunal. ${ }^{37}$

La Comisión revisó su estrategia procesal para pasar a demandar de manera general ambos tipos de sanciones de manera cumulativa, al darse cuenta de su potencial, porque muchos Estados alargaban el incumplimiento hasta el último momento antes de la sentencia y, por tanto, las multas a tanto alzado podían resultar también útiles para agilizar el cumplimiento antes de que se produjese la sentencia. ${ }^{38}$

La cuantía de las sanciones que propone la Comisión viene guiada por tres criterios fundamentales (respaldados por el Tribunal): la gravedad de la infracción, la duración de la misma y la necesidad de asegurar el efecto disuasorio de la sanción para evitar la reincidencia.

Desde el principio, la Comisión dejó claro que tenía en cuenta múltiples parámetros para medir la gravedad de la infracción como es el que afecte a intereses generales, algo que parece evidente en materia medioambiental, y ella misma ponía como ejemplo un caso de contaminación por no seguir los estándares de la UE. ${ }^{39}$ Esos criterios se han visto desarrollados con el tiempo y la jurisprudencia del TJUE y actualmente se consideran graves las infracciones

\footnotetext{
${ }^{36}$ STJUE de 19 de octubre de 2011, República Francesa c. Comisión Europea, asunto T-139/06, ECLI:EU:T:2011:605.

${ }^{37}$ A raíz de este caso se modificó el Estatuto del TJUE para que la jurisdicción cuando un Estado no estuviera de acuerdo con la decisión de la Comisión no quedará en manos del Tribunal General, sino del Tribunal de Justicia: Reglamento (UE) 2019/629 del Parlamento Europeo y del Consejo, de 17 de abril de 2019, por el que se modifica el Protocolo n. ${ }^{\circ} 3$ sobre el Estatuto del Tribunal de Justicia de la Unión Europea, DOUE L 111 de 25.4.2019, pp. 1-3.

38 Comunicación de la Comisión sobre la aplicación del artículo 228 del Tratado CE (SEC/2005/1658). Disponible en: <https://eur-lex.europa.eu/legalcontent/ES/ALL/?uri=CELEX\%3A52005SC1658> [Última consulta, 5 de mayo de 2020].

${ }^{39}$ Comunicación sobre la aplicación del artículo 171 del Tratado CE (96/C 242/07), DOUE C 242 de 21/08/1996, pp. 6-8. Disponible en: <https://eurlex.europa.eu/LexUriServ/LexUriServ.do?uri=CELEX:31996Y0821(03):ES:HTML> [Última consulta, 5 de mayo de 2020].
} 
que supongan un daño grave o irreparable a la salud humana o al medio ambiente.

Según la Comisión, las sanciones que propone al TJUE deben ser previsibles para los Estados y deben calcularse según un método que respete tanto el principio de proporcionalidad como el de igualdad de trato entre Estados miembros, ${ }^{40}$ para lo que ha elaborado una serie de funciones y tablas con diferentes coeficientes por Estados para tener en cuenta su capacidad de pago. ${ }^{41}$ Si bien es necesario aclarar que el mecanismo del artículo 260 busca tener sobre todo un carácter disuasorio más que el ser utilizado. Otros mecanismos como la cofinanciación o la acción discursiva se aplican continuamente en paralelo, porque las sanciones no siempre son la mejor herramienta y hay autores que consideran que el uso excesivo de ese instrumento podría obstaculizar la legitimidad de la UE. ${ }^{42}$ Sin duda es una herramienta de la que la Comisión no puede abusar en el delicado equilibrio político en el que lleva a cabo sus funciones. ${ }^{43}$

Se trata de un instrumento de ultima ratio ${ }^{44}$ por si falla completamente el diálogo y, por tanto, es poco frecuente su uso por parte de la Comisión Europea. Por ejemplo, en 2018, mientras que la Comisión planteó 10 recursos de

\footnotetext{
${ }^{40}$ Comunicación de la Comisión - Aplicación del artículo 260, apartado 3, del TFUE (2011/C 12/01), DOUE C 12 de 15.1.2011, pp. 1-5. Disponible en: <https://eur-lex.europa.eu/legalcontent/ES/TXT/?qid=1588847913431\&uri=CELEX:52011XC0115(01)> [Última consulta, 5 de mayo de 2020].

${ }^{41}$ Comunicación de la Comisión - Modificación del método de cálculo de los pagos a tanto alzado y las multas coercitivas diarias propuestos por la Comisión en los procedimientos de infracción ante el Tribunal de Justicia de la Unión Europea, C/2019/1396, DOUE C 70 de 25.2.2019, pp. 1-7. Disponible en: <https://eur-lex.europa.eu/legalcontent/ES/TXT/?qid=1588847233764\&uri=CELEX:52019XC0225(01)> [Última consulta, 5 de mayo de 2020].

42 Gerda Falkner, "Fines against member states: An effective new tool in EU infringement proceedings?", en Comparative European Politics, vol. 14, 2016, pp. 36-52. Disponible en: $<$ https://doi.org/10.1057/cep.2015.8> [Última consulta, 5 de mayo de 2020].

43 Jan Darpö, "The Commission: A Sheep in Wolf's Clothing?: On Infringement Proceedings as a Legal Device for the Enforcement of EU Law on the Environment, Using Swedish Wolf Management as an Example", en Journal for European Environmental and Planning Law, vol. 13, núm 3, 2016, pp. 270-293. Disponible en: <https://doi.org/10.1163/18760104-01303004> [Última consulta, 5 de mayo de 2020].

${ }^{44}$ Incluso podría considerarse la ultima ratio de la ultima ratio, puesto que el Tribunal de Justicia de las Comunidades Europeas definió el recurso de incumplimiento previo como la "ultima ratio que permite hacer valer los intereses comunitarios consagrados por el Tratado contra la inercia y la resistencia de los Estados miembros". STJCE de 15 de julio de 1960, Reino de los Países Bajos c. Alta Autoridad de la Comunidad Europea del Carbón y del Acero, asunto 25/59, ECLI:EU:C:1960:34.
} 
incumplimiento contra Estados conforme al artículo 258 TFUE por cuestiones medioambientales, sólo inició uno conforme al artículo 260.2. Es importante destacar que el incumplimiento de los Estados en materia de medio ambiente también puede ser perseguido ante los tribunales nacionales, pero esto puede depender de diferentes factores, y el rol de la Comisión en este sentido es irremplazable. ${ }^{45}$

A finales de 2018, 99 procedimientos de infracción seguían abiertos después de un fallo del Tribunal porque la Comisión consideró que los Estados miembros afectados aún no habían cumplido las sentencias. Más de la mitad de estos casos (53) estaban relacionados con el medio ambiente..$^{46}$ Un estudio realizado de las 32 primeras sentencias conforme al artículo 260.2 dio como resultado que 13 de las mismas, es decir, un $40,6 \%$ se habían dado en materia medioambiental. ${ }^{47}$

En 2018, el Tribunal emitió 5 sentencias por «doble incumplimiento» de las que cuatro tenían que ver con asuntos medioambientales. ${ }^{48}$ En concreto, se impusieron multas a Grecia, ${ }^{49}$ Italia ${ }^{50}$ y España ${ }^{51}$ por haber tardado en aplicar las normas de la Unión sobre recogida y tratamiento de aguas residuales, y a Eslovaquia, ${ }^{52}$ por su retraso en aplicar las normas sobre el vertido de residuos.

\footnotetext{
${ }^{45}$ Andreas Hofmann "Left to interest groups? On the prospects for enforcing environmental law in the European Union", en Environmental Politics, vol. 28, 2019, pp. 342-364, $<$ https://doi.org/10.1080/09644016.2019.1549778> [Última consulta, 5 de mayo de 2020].

${ }^{46}$ Comisión Europea, Monitoring the Application of Union Law 2018 Annual Report. Part I: general statistical overview, 2019, p. 22. Disponible en: <https://ec.europa.eu/info/sites/info/files/report2018-commission-staff-working-document-monitoring-application-eu-law-general-statisticaloverview-part1 0.pdf>[Última consulta, 5 de mayo de 2020].

47 Gerda Falkner, "A casual...", cit., p. 779.

Brian Jack "Article 260(2) TFEU: An Effective Judicial Procedure for the Enforcement of Judgements?", en European Law Journal, vol. 19, núm. 3, 2013, pp. 404-421. Disponible en: $<$ https://doi.org/10.1111/eulj.12030> [Última consulta, 5 de mayo de 2020] subraya que el mecanismo del artículo 260.2 se da en casos fundamentalmente con cariz económico (por ejemplo, ayudas de Estado) y medioambiental.

48 Tribunal de Justicia de la Unión Europea, Informe anual 2018. Panorámica del año, 2019. Disponible en: <https://curia.europa.eu/icms/upload/docs/application/pdf/201906/20190650 ra pan es 2019-06-06 09-48-20 48.pdf> [Última consulta, 5 de mayo de 2020]. 49 Sentencia TJUE de 22 de febrero de 2018, Comisión Europea c. República Helénica, asunto C-328/16, ECLI:EU:C:2018:98.

50 STJUE de 31 de mayo de 2018, Comisión Europea c. República Italiana, asunto C-251/17, ECLI:EU:C:2018:358.

51 STJUE de 25 de julio de 2018, Comisión Europea c. Reino de España, asunto C-205/17, ECLI:EU:C:2018:606.

52 STJUE de 4 de julio de 2018, Comisión Europea c. República Eslovaca, asunto C-626/16, ECLI:EU:C:2018:525.
} 
En 2019, de los dos recursos de esta naturaleza que resolvió el Tribunal uno fue en un asunto medioambiental. En concreto, se declaró que Irlanda ${ }^{53}$ había incumplido la sentencia ${ }^{54}$ en la que se le condenó por permitir la construcción de parques eólicos sin haber llevado a cabo una evaluación previa de las repercusiones sobre el medio ambiente a través de una regularización a posteriori, siendo éste el caso en Derrybrien.

En 2020, de las dos sentencias que ha habido resolviendo este tipo de recursos, una tenía que ver con temas medioambientales. ${ }^{55}$ En concreto, se ha condenado a Grecia ${ }^{56}$ por incumplir la sentencia que le condenaba por no tomar las medidas necesarias para la protección de las aguas contra la contaminación por nitratos procedentes de fuentes agrícolas. ${ }^{57}$ Este caso es un ejemplo en el que el Tribunal sólo impuso una multa a tanto alzado, porque desde el momento en el que se interpuso el recurso hasta la sentencia Grecia cumplió la sentencia original, con lo cual una multa coercitiva no tenía sentido.

Una de las razones para que se den estos recursos es que los gobiernos tienden a retrasar las inversiones necesarias, por ejemplo, para eliminar de forma segura los desechos peligrosos, o tomar medidas que sean impopulares en el sector agrario. Además, cuando finalmente se avecinan las multas, es imposible actuar de manera rápida porque hay que crear infraestructuras, elaborar planes de acción, etc. A esto se suma que puede ser inherentemente difícil lograr alinear a una multitud de actores de nivel inferior para un cumplimiento rápido cuando no son competencias estatales sino de los ayuntamientos, que pueden no tener presupuesto para llevar a cabo determinadas medidas. ${ }^{58}$

Un ejemplo de esto sería el caso de España con el tratamiento de los residuos urbanos. En 2011, el Tribunal declaró que España había incumplido sus obligaciones en virtud de la Directiva sobre el tratamiento de las aguas residuales

53 STJUE de 12 de noviembre de 2019, Comisión Europea c. Irlanda, asunto C-261/18, ECLI:EU:C:2019:955.

${ }^{54}$ STJUE de 3 de julio de 2008, Comisión Europea c. Irlanda, asunto C-215/06, EU:C:2008:380.

${ }^{55}$ Hasta el 3 de mayo de 2020.

56 STJUE de 27 de febrero de 2020, Comisión Europea c. República Helénica, asunto C-298/19, ECLI:EU:C:2020:133.

57 STJUE de 23 de abril de 2015, Comisión Europea c. República Helénica, C-149/14, EU:C:2015:264.

${ }^{58}$ Gerda Falkner, "A casual...", cit., p. 782. 
urbanas, ${ }^{59}$ ya que no había garantizado la recogida y el tratamiento de las aguas residuales urbanas en, respectivamente, 6 y 37 aglomeraciones con una población de más de 15000 habitantes. ${ }^{60}$ En 2018, el Tribunal consideró que España persistía en el incumplimiento porque 17 de las 43 aglomeraciones afectadas todavía no habían sido equipadas con sistemas para recolectar o tratar aguas residuales urbanas. ${ }^{61} \mathrm{El}$ Tribunal condenó a España a pagar una suma a tanto alzado de 12 millones de euros por el tiempo transcurrido entre la primera y segunda sentencias, montante para el que tuvo en cuenta la considerable duración de la infracción. También se condenó a España a pagar una multa coercitiva de un importe de $10950000 €$ por cada semestre de retraso en la aplicación de las medidas necesarias para dar cumplimiento a la segunda sentencia. ${ }^{62}$

Como el incumplimiento estaba compuesto por infracciones en múltiples localidades, como ocurre a veces con las normas medioambientales, el Tribunal estableció que el importe efectivo debería calcularse al final de cada período de seis meses reduciendo el importe total correspondiente a cada uno de esos períodos en un porcentaje equivalente a la proporción que represente el número de habitantes de las aglomeraciones cuyos sistemas colectores y/o de tratamiento de las aguas residuales urbanas hubieran sido objeto de las adaptaciones necesarias, en relación con el número de habitante de las aglomeraciones que no dispusieran de tales sistemas en la fecha en que se dictó la sentencia.

Esto es algo inusual porque normalmente la multa coercitiva debe exigirse en su totalidad hasta que el Estado miembro haya adoptado todas las medidas

\footnotetext{
59 Directiva 91/271/CEE del Consejo, de 21 de mayo de 1991, sobre el tratamiento de las aguas residuales urbanas, DOUE L 135 de 30.5.1991, pp. 40-52.

60 STJUE de 14 de abril de 2011, Comisión Europea c. Reino de España, asunto C-343/10, EU:C:2011:260.

61 STJUE de 25 de julio de 2018, Comisión Europea c. Reino de España, asunto C-205/17, ECLI:EU:C:2018:606. Véase Eric Naim-Gesbert, « De la toujours chaotique transposition de la directive 91/271/CEE (eaux urbaines résiduaires) : note sur CJUE 25 juillet 2018, Commission c/Espagne, aff C-205/17 », en Revue Juridique de l'Environnement, vol. 43, núm. 4, 2018, pp. 848-851.

62 Es necesario aclarar que el Tribunal sólo puede condenar y exigir responsabilidad a España en su conjunto. Sin embargo, a nivel interno el Estado puede exigir el pago de esas multas a las administraciones responsables del incumplimiento conforme al Real Decreto 515/2013, de 5 de julio, por el que se regulan los criterios y el procedimiento para determinar y repercutir las responsabilidades por incumplimiento del Derecho de la Unión Europea, BOE núm. 161, de 6 de julio de 2013, pp. 50508-50519.
} 
necesarias para poner fin al incumplimiento declarado por completo, pero en determinados casos puede concebirse una sanción que tenga en cuenta los progresos eventualmente realizados por el Estado miembro en el cumplimiento de sus obligaciones.

En sus alegaciones, España intentó justificar que sus esfuerzos para dar cumplimiento a la sentencia habían sido constantes y se seguían realizando, pero el Tribunal dictaminó que la justificación que España aducía de que el retraso en la ejecución de la sentencia obedecía a dificultades jurídicas y económicas internas no podían tenerse en cuenta, porque un Estado miembro no puede alegar dificultades de orden interno para justificar el incumplimiento del Derecho de la UE.

En todos los casos mencionados puede observarse que la Comisión prefiere no recurrir al Tribunal de Justicia y sólo tras un amplio diálogo de varios años sin un cumplimiento efectivo termina planteando este tipo de recursos. Además, todas las sentencias estudiadas desde 2018 tienen su origen en el incumplimiento de directivas de los años noventa (en un caso de los ochenta) para cuyo cumplimiento los Estados han contado con más de veinte años. ${ }^{63}$ En pocos casos parece que pueda estar más justificado interponer este tipo de recursos que en los relacionados con el medio ambiente, dado su impacto en la naturaleza y en particular en la salud humana. La Comisión parece considerar lo mismo ya que es por este motivo por el que más recursos de "doble incumplimiento" plantea.

\section{MEDIDAS EN CASO DE INCUMPLIMIENTO DE LAS MEDIDAS PROVISIONALES DEL TRIBUNAL DE JUSTICIA DE LA UNIÓN EUROPEA}

\section{Las medidas provisionales en materia medioambiental}

\footnotetext{
${ }^{63}$ El dilatado espacio de tiempo entre que se inicia el incumplimiento y el Tribunal impone sanciones, así como los limitados recursos de supervisión de la Comisión Europea son razones que socaban el poder disuasorio de este mecanismo. Véase Pål Wennerås, "Sanctions against Member States under Article 260 TFEU: alive, but not kicking?", en Common Market Law Review, vol. 49, núm. 1, 2012, pp. 145-175 y Pål Wennerås, "Making effective use of Article 260 TFEU", en András Jakab y Dimitry Kochenov (eds.), The Enforcement of EU Law and Values, Oxford University Press, 2017, pp. 79-111, DOI:10.1093/acprof:oso/9780198746560.003.0006. El tiempo que pueden prolongarse estos casos sobre todo en su período precontencioso ha sido muy criticado por la doctrina, véase Ludwig Krämer Environmental judgements by the Court of Justice and their duration, Research Papers in Law/Cahiers juridiques No 4/2008, College of Europe, 2008.
} 
El equilibrio de determinados ecosistemas tiende a ser muy delicado, por esta razón existen múltiples normas de la UE para proteger flora, fauna y espacios naturales. El incumplimiento de estas normas puede en un corto período de tiempo terminar con una especie o crear daños de tal magnitud en un ecosistema que se produzca una pérdida irreversible. Esto no casa bien con los largos plazos que hemos descrito que se dan en la mayoría de los casos que llevan a la Comisión Europea a impulsar la toma de medidas coercitivas. Tanto las administraciones nacionales como europeas funcionan a un ritmo lento articulado en torno a procesos y una no desdeñable carga burocrática. ¿Cuál puede ser entonces la respuesta a un daño irreparable e inminente?

Según el artículo 279 TFUE, el TJUE podrá ordenar las medidas provisionales necesarias en los asuntos de que esté conociendo, incluidos los recursos de incumplimiento. ${ }^{64}$ Algunos autores proponen que la Comisión pudiera dictar ella misma medidas provisionales en la fase pre-contenciosa porque si no durante el plazo de desarrollo de la misma se puede producir un daño irreparable al medio ambiente, lo que conlleva que en la mayoría de los casos las medidas provisionales no lleguen a prevenir el daño, sino sólo a limitarlo. ${ }^{65}$ No obstante, un avance en ese sentido parece poco probable.

Conforme al artículo 160.3 del Reglamento de Procedimiento del Tribunal de Justicia, la demanda de estas medidas provisionales planteada por la Comisión especificará el objeto del litigio, las circunstancias que den lugar a la urgencia, así como los antecedentes de hecho y los fundamentos de Derecho que justifiquen a primera vista la concesión de la medida provisional solicitada. El Presidente resolverá él o atribuirá sin dilación la decisión al Tribunal.

La finalidad del procedimiento de medidas provisionales es garantizar la plena eficacia de la futura decisión definitiva, para evitar una laguna en la protección jurisdiccional que ofrece el Tribunal de Justicia. El objeto de las medidas es salvaguardar, durante el procedimiento ante el Tribunal, los intereses de una de las partes en el litigio con el fin de no privar de eficacia a la sentencia que se

\footnotetext{
${ }^{64}$ Véase Ana María Chocrón Giráldez, "Proceedings for Interim Measures before the European Court of Justice", en Good Practices in Social Law, 2015, pp. 217-227.

65 Levente Borzsák, The Impact of Environmental Concerns on the Public Enforcement Mechanism under EU Law: Environmental Protection in the 25th Hour, Kluwer Law International B.V., 2011, p. 147.
} 
dicte en el asunto principal, pero sin prejuzgar la decisión sobre el fondo del asunto.

Según jurisprudencia reiterada, el Tribunal únicamente puede adoptar tales medidas si se demuestra que su concesión está justificada a primera vista de hecho y de derecho (fumus boni iuris) y que son urgentes, en el sentido de que para evitar que los intereses de la parte demandante sufran un perjuicio grave e irreparable es necesario que tales medidas sean acordadas y surtan efectos desde antes de que se resuelva sobre el procedimiento principal. El Tribunal en su decisión debe ponderar los intereses en juego.

En ninguna de las normas mencionadas se detalla la naturaleza que dichas medidas deben tener. ${ }^{66}$ Mientras en la sentencia que resuelve el recurso de incumplimiento el Tribunal sólo puede declarar éste y es el Estado el que determina las medidas para cumplir, en el caso de las medidas provisionales el Tribunal tiene mucho mayor margen al poder optar por establecer cualquier tipo de medida idónea para cumplir su finalidad. ${ }^{67}$

El primer caso en el que el Tribunal decidió la aplicación de medidas provisionales fue en 1957.68 Se calcula que ha podido tener en torno a 1000 casos en los que se hayan solicitado, ${ }^{69}$ pero es mucho más común que estas medidas se den en casos contra las instituciones europeas (un recurso de anulación u omisión) que en recursos de incumplimiento. Este tipo de medidas provisionales casi nunca se solicitan, ya que la Comisión es muy consciente de

\footnotetext{
${ }^{66}$ Algunos autores han criticado que no exista una lista exhaustiva de posibles medidas. Véase Itziar Giménez Sánchez y Juan Antonio Robles Garzón, La eficacia de las sentencias dictadas por el TJCE, Aranzadi, Pamplona, 2003, p. 180. No obstante, la propia naturaleza del ordenamiento de la UE que afecta a ramas tan dispares del ordenamiento hace que la existencia de un numerus clausus pudiera resultar contraproducente.

${ }^{67}$ Margot Horspool y Matthew Humphreys, European Union Law, Oxford University Press, 2012, p. 231.

${ }^{68}$ Auto del TJCE de 4 de diciembre de 1957, Firma J. Nold K.G. C. Alta Autoridad de la Comunidad Europea del Carbón y del Acero, asunto 18/57 R, ECLI:EU:C:1957:11.

${ }^{69}$ Véase Luca Prete, "Can't See the Forest for the Trees? Penalties Under Article 279 TFEU", en Yearbook on Procedural Law of the Court of Justice of the European Union-2019, MPILux Research Paper, 2020, pp. 157-170, p. 157. Disponible en: $<$ http://dx.doi.org/10.2139/ssrn.3530773> [Última consulta, 5 de mayo de 2020].

Cabe destacar para entender mejor este número que ésas pueden darse sólo en los recursos directos, pero no en las cuestiones prejudiciales, porque en ellas correspondería al juez nacional el decidirlas.
} 
la reticencia del Tribunal a ordenar a los Estados miembros que actúen o se abstengan de actuar en términos provisionales. ${ }^{70}$

No fue hasta 2006 que el Tribunal aprobó la concesión de medidas provisionales en un caso medioambiental. ${ }^{71}$ Se suspendió la aplicación de la Ley núm. 36/2006 de la región de Liguria, de 31 de octubre de 2006, que desarrollaba la excepción prevista en el artículo 9 de la Directiva 79/409/CEE, ${ }^{72}$ relativa a la conservación de las aves silvestres, durante la temporada de caza 2006/2007. La Comisión quería evitar que la sentencia llegará tarde para impedir la caza de estorninos en esa temporada. Cabe destacar que el Presidente tardó sólo seis días en tomar esta decisión tras la demanda de la Comisión.

El Tribunal analizó si se cumplían los requisitos relevantes en lo relativo al fumus boni iuris, la urgencia y el equilibrio de intereses. En concreto, sobre la urgencia, el Presidente recordó que cualquier actividad de caza puede perturbar la vida silvestre y que, en muchos casos, puede condicionar el estado de conservación de la especie en cuestión. Por lo tanto, en su opinión parecía que la caza continua de estorninos podría causar daños graves e irreparables a la fauna y patrimonio ornitológico.

Un caso muy similar se daría poco después en Italia cuando el Tribunal suspendió la aplicación del artículo 4.1 de la Ley de la región de Lombardía núm. 24 , de 30 de julio de 2008, que regula el régimen de excepción previsto en el artículo 9 de la misma Directiva 79/409/CEE modificada para la temporada de caza 2009/2010 por la Ley de la región de Lombardía núm. 21, del 16 de septiembre de $2009 .{ }^{73}$ El Presidente recordó que la legislación comunitaria sobre la conservación de las aves silvestres debía interpretarse a la luz del principio de precaución, que es uno de los fundamentos de la política de protección de alto nivel aplicada por la UE en el ámbito del medio ambiente. Además, constató que al evaluar los intereses contrapuestos en juego, si el interés invocado por la

70 Daniel Sarmiento, "Interim Revolutions", Verfassungsblog, 22/10/2018. Disponible en: $<$ https://verfassungsblog.de/interim-revolutions/> [Última consulta, 5 de mayo de 2020].

${ }^{71}$ Auto del Presidente del Tribunal de Justicia de 19 de diciembre de 2006, Comisión de las Comunidades Europeas c. República Italiana, asunto C-503/06 R, ECLI:EU:C:2006:800

72 Directiva 79/409/CEE del Consejo, de 2 de abril de 1979, relativa a la conservación de las aves silvestres, DOUE L 103 de 25.4.1979, pp. 1-18.

${ }^{73}$ Auto del Presidente del Tribunal de Justicia de 10 de diciembre de 2009, Comisión Europea c. República Italiana, asunto C-573/08 R, ECLI:EU:C:2009:775. 
Comisión, que consistía en evitar daños graves e irreparables al patrimonio ornitológico de la UE, se compara con el interés de los cazadores, el interés vinculado a la protección del patrimonio común de la UE, basado en justificaciones ecológicas, es considerable en sí mismo, y el interés de los cazadores no parecía tener un valor mayor que éste.

En 2008, el Tribunal ordenó a Malta abstenerse de adoptar medidas por las que se aplicara la excepción del artículo 9 de la Directiva 79/409/CEE para la caza de codornices y de tórtolas durante su período migratorio de primavera de ese año. ${ }^{74}$ La Comisión solicitó las medidas antes de que Malta adoptara una norma que lo permitiera, pero después de que ésta hubiera iniciado los pasos preparatorios (pedir un informe a un comité de expertos). Malta argumentó que si tomará la medida la Comisión podría solicitar que no se aplicará pero que todavía no lo había hecho. No obstante, el Presidente del Tribunal consideró que, además de la suspensión de un acto, las medidas provisionales pueden revestir cualquier otra forma que esté en línea con la consecución de su objetivo.

En los tres casos anteriores, el Tribunal terminó dando la razón a la Comisión en sus sentencias. ${ }^{75}$ Es muy poco probable que la Comisión hubiera pedido medidas provisionales de no tener la convicción de que terminaría ganado los casos y de que sus argumentos jurídicos eran muy sólidos.

En 2007, el Tribunal ordenó a Polonia abstenerse de comenzar o suspender determinadas actividades para la construcción de una carretera que podían no ser coherentes con la Directiva de hábitats, porque la implementación del proyecto corría el riesgo de alterar permanentemente las características naturales del sitio. ${ }^{76}$ Finalmente, Polonia optó por una ruta alternativa para la

\footnotetext{
${ }^{74}$ Auto del Presidente del Tribunal de Justicia de 24 de abril de 2008, Comisión Europea c. República de Malta, asunto C-76/08 R, ECLI:EU:C:2008:252.

${ }^{75}$ STJUE de 15 de mayo de 2008, Comisión de las Comunidades Europeas c. República Italiana, asunto C-503/06, ECLI:EU:C:2008:279; STJUE de 15 de julio de 2010, Comisión Europea C. República Italiana, asunto C-573/08, ECLI:EU:C:2010:428; y STJUE de 10 de septiembre de 2009, Comisión de las Comunidades Europeas c. República de Malta, asunto C-76/08, ECLI:EU:C:2009:535.

76 Auto del Presidente del Tribunal de Justicia de 18 de abril de 2007, Comisión Europea c. República de Polonia, asunto C-193/07 R, ECLI:EU:C:2007:218.
} 
carretera lo que satisfizo las expectativas de la Comisión y por tanto el Tribunal no tuvo que resolver el caso principal. ${ }^{77}$

Es importante apreciar los límites significativos del procedimiento de medidas provisionales en materia medioambiental. En particular, el procedimiento solo puede utilizarse si es evidente que la conducta (ya sea acto u omisión) por parte del Estado demandado provocaría un daño ambiental irreparable en el período anterior a la sentencia sustantiva del TJUE. Esto descarta efectivamente la posibilidad de que sea un instrumento útil en una serie de contextos que de otra manera podrían describirse como urgentes desde una perspectiva de protección ambiental y/o salud pública, por ejemplo, infracciones de la legislación de calidad del aire o de la legislación destinada a combatir la eutrofización del agua. ${ }^{78}$

\section{Las multas coercitivas por incumplimiento de las medidas provisionales en el caso "Białowieża"}

Visto ya el contexto general del uso de las medidas provisionales en materia medioambiental por el TJUE, conviene centrar la atención en el caso Białowieża (C-441/17 R) que ha supuesto una gran innovación en este ámbito.

El bosque de Białowieża, situado entre Polonia y Bielorrusia, es considerado el último gran bosque virgen (primeval) de Europa. Es una reserva natural de gran importancia por lo que fue declarada Reserva de la Biosfera por la UNESCO y Patrimonio de la Humanidad, y forma parte de la red Natura 2000. El bosque se caracteriza por tener grandes cantidades de madera muerta y de árboles muy longevos que sirven como sustento para gran número de animales. Los árboles muertos, que en la gestión de otro tipo de bosques podría ser pertinente retirar, aquí es necesario que permanezcan porque es parte del equilibrio del ecosistema. El plan de conservación de la zona limitaba, por tanto, la extracción maderera de la zona. No obstante, en 2016 se modificó para elevar la cantidad de árboles que se podían retirar y talar para luchar contra la propagación de un tipo de escarabajos de la madera (Ips typographus).

\footnotetext{
77 Auto del Presidente del Tribunal de Justicia de 25 de agosto de 2009, Comisión Europea c. República de Polonia, asunto C-193/07 R, ECLI:EU:C:2009:495.

78 Martin Hedemann-Robinson, Enforcement of European Union Environmental Law: Legal Issues and Challenges, Routledge, 2015 (2ª Edición), pp. 136-137.
} 
Esta medida fue muy criticada por expertos ${ }^{79} \mathrm{y}$ organizaciones de protección del medio ambiente ${ }^{80}$ que la consideraban contraproducente porque creían que era mucho mejor que el bosque se autorregulara. La Comisión estaba de acuerdo y comenzó un procedimiento por infracción de la Directiva de hábitats y de la de aves, que desafortunadamente no consiguió la modificación de las medidas. Mientras tanto se procedió a la retirada y tala de un número considerable de árboles.

La Comisión presentó un recurso de incumplimiento y demandó la concesión de medidas provisionales, algo que como se ha visto es excepcional, pero estaba totalmente justificado en el caso dado los daños irreparables que se estaban produciendo a un ecosistema que requería especial protección. El bosque se había conservado durante cientos de años y una importante parte del mismo podía desaparecer en apenas unos meses.

La Comisión solicitó que se ordenase a Polonia que pusiera fin, salvo en caso de amenaza para la seguridad pública, a las operaciones de gestión forestal activa en una serie de zonas, a la retirada de píceas centenarias muertas y a la tala de árboles en el marco del aumento del volumen de madera explotable en el lugar Natura 2000 Puszcza Białowieska. El Vicepresidente del Tribunal de Justicia rápidamente estimó la demanda. ${ }^{81}$

No obstante, la tala continuó a gran velocidad y las autoridades polacas se manifestaron en contra de seguir las indicaciones del Tribunal..$^{82}$ Esto llevó a la Comisión a tomar una decisión sin precedentes que fue solicitar al Tribunal de Justicia que impusiera asimismo a Polonia el pago de una multa coercitiva para el caso de que no atendiera las medidas provisionales dictadas.

\footnotetext{
79 Grzegorz Mikusińskiab, Jakub Witold Bubnickic, Marcin Churskic, Dorota, Czeszczewikd, Wiesław Walankiewiczd, y Dries P. J. Kuijperc, "Is the impact of loggings in the last primeval lowland forest in Europe underestimated? The conservation issues of Białowieża Forest", en Biological Conservation, vol. 227, 2018, pp. 266-274. Disponible: $<$ https://doi.org/10.1016/i.biocon.2018.09.001> [Última consulta, 5 de mayo de 2020].

80 ClientEarth, Saving Białowieża. Disponible en: <https://www.clientearth.org/savingbialowieza/> [Última consulta, 5 de mayo de 2020].

${ }^{81}$ Auto del Vicepresidente del Tribunal de Justicia de 27 de julio de 2017, Comisión Europea c. República de Polonia, asunto C-441/17 R, EU:C:2017:622.

82 Véase Joanna Berendt, "Defying E.U. Court, Poland Is Cutting Trees in an Ancient Forest," New York Times, 31/07/2017. Disponible en: $<$ https://www.nytimes.com/2017/07/31/world/europe/poland-bialowieza-forest-bisonlogging.html> [Última consulta, 5 de mayo de 2020].
} 
La relevancia de una decisión en ese sentido llevó a que se elevara a la Gran Sala. El Tribunal optó por conceder la demanda de la Comisión, ${ }^{83}$ a pesar de que en ninguna norma (ni en los Tratados, ni en el Estatuto o el Reglamento del Tribunal) se recogiera específicamente esa posibilidad. En esta decisión puede apreciarse el rol del TJUE para suplir las lagunas del Derecho comunitario como lo hizo al fijar principios como el de la primacía y el efecto directo, para asegurar que el Derecho de la UE tiene un efecto útil.

EI TJUE recordó que la finalidad del procedimiento de medidas provisionales, como se ha explicado, es garantizar la plena eficacia de la futura decisión definitiva, al objeto de evitar una laguna en la protección jurisdiccional que depara el Tribunal y en el sistema de vías de recurso establecido por el Tratado. Una parte puede no solo solicitar la suspensión de la ejecución del acto impugnado en el asunto principal, sino también invocar el artículo 279 TFUE a fin de solicitar otro tipo de medidas provisionales que pueden revestir muchas formas diferentes.

El Tribunal argumentó que el artículo 279 TFUE le confiere competencia para ordenar toda medida provisional que considere necesaria para garantizar la plena eficacia de la decisión definitiva. El juez debe asegurarse de que las medidas que se propone ordenar son lo suficientemente eficaces como para alcanzar su objetivo. A tal efecto este artículo concede al juez un amplio margen de apreciación que le permite, según las circunstancias de cada caso concreto, precisar el objeto y el alcance de las medidas provisionales. El juez que conoce de las medidas provisionales ha de poder garantizar la eficacia de una orden conminatoria dirigida a una parte adoptando cualquier medida que tenga por objeto hacer respetar por esa parte el auto de medidas provisionales. De estos razonamientos, el Tribunal concluyó que tal medida podía consistir en prever la imposición de una multa coercitiva en caso de que dicha orden conminatoria no fuera respetada por la parte de que se trate.

Polonia argumentó que solo el artículo 260 TFUE habilitaba al Tribunal para imponer sanciones a los Estados y deducía de ello que, si la Comisión estimaba que había incumplido las obligaciones dimanantes del auto, le correspondía

\footnotetext{
${ }^{83}$ Auto del Tribunal de Justicia (Gran Sala) de 20 de noviembre de 2017, Comisión Europea c. República de Polonia, asunto C-441/17 R, ECLI:EU:C:2017:877.
} 
interponer previamente un recurso por incumplimiento, y que, solo en el supuesto de que el Tribunal estimara ese recurso y de que Polonia no ejecutara la resolución del Tribunal, estaría la Comisión habilitada para formular recurso en virtud del artículo 260 TFUE. No obstante, el Tribunal constató, primero, que una multa coercitiva no podía, en las circunstancias del asunto, considerarse una sanción y, segundo, que la interpretación de Polonia del sistema de vías de recurso y del procedimiento sobre medidas provisionales tendría por efecto reducir considerablemente la posibilidad de que el procedimiento alcanzara su objetivo en caso de incumplimiento por parte del Estado, como se puede deducir de los explicado anteriormente.

El Tribunal subrayó que el hacer respetar por un Estado las medidas provisionales adoptadas, previendo la imposición de una multa coercitiva en caso de incumplimiento, tenía por objeto garantizar la aplicación efectiva del Derecho de la UE, la cual es inherente al valor del Estado de Derecho consagrado en el artículo 2 TUE y en el que se basa la UE. Esta referencia puede entenderse también como un aviso velado a Polonia que se encuentra en un proceso de supervisión por incumplimiento del Estado de Derecho. En ese sentido, podría tildarse al TJUE de cierto activismo judicial. ${ }^{84}$

El Tribunal consideró la perspectiva de la imposición de una multa coercitiva contribuiría a disuadir al Estado concernido de no respetar las medidas provisionales decretadas, algo similar a lo que se ha visto que se pretende a través del mecanismo del artículo 260 TFUE. Este nuevo mecanismo reforzaría la eficacia de las medidas y garantizaría la plena eficacia de la decisión definitiva, situándose así completamente en "la órbita del objetivo del artículo 279 TFUE”.

El Tribunal consideraba que no cabía excluir el riesgo de que, si el segundo auto debiera limitarse a confirmar las medidas ordenadas mediante el auto anterior, su eficacia siguiera siendo limitada, por lo que debía reforzar la eficacia de las medidas provisionales ordenadas, previendo la imposición de una multa coercitiva en caso de que Polonia no respetara de forma inmediata y plena

\footnotetext{
${ }^{84}$ Véase Mary L. Volcansek, "The European Court of Justice: Supranational policy-making", en West European Politics, vol. 15, núm. 1992, 2007, pp. 109-121. Disponible en: <https://doi.org/10.1080/01402389208424924> [Última consulta, 5 de mayo de 2020].
} 
dichas medidas provisionales, a fin de disuadir a ese Estado de que se retrasara en acomodar su comportamiento al auto en cuestión.

Cabe destacar que el Tribunal no impuso directamente la multa sino que creó un mecanismo más complejo, de nuevo aspirando a que no fuera necesario ponerlo en práctica sino que tuviera un efecto disuasorio. Ordenó a Polonia que comunicara a la Comisión, a más tardar quince días después de la notificación del auto, todas las medidas que adoptara para el pleno respeto de las medidas provisionales. Si la Comisión considerara que Polonia no las había respetado plenamente podría entonces solicitar que se reanudara el procedimiento. El Tribunal se pronunciaría, mediante un nuevo auto, sobre la eventual violación, y, en su caso, ordenaría a Polonia que pagara a la Comisión una multa coercitiva de al menos $100000 €$ por día, a partir del día de la notificación del segundo auto a Polonia y hasta que ésta lo respetase o se dictara la sentencia. Según Sarmiento, la forma en que el TJUE maneja este nuevo poder es bastante matizada e inteligente al no imponer la multa de pago en concreto, sino en abstracto. En su opinión, este es un movimiento inteligente por parte del Tribunal, con un enfoque típico de "palo y zanahoria" para un expediente sensible. ${ }^{85}$ Es necesario aclarar que la Comisión nunca puso en marcha este mecanismo, pero el precedente ya se ha creado para futuras situaciones similares. Finalmente el Tribunal de Justicia en su sentencia sobre este caso constató que efectivamente se había producido un incumplimiento por parte de Polonia. ${ }^{86}$

A pesar del "salto procesal" dado por el TJUE en este caso, su innovadora interpretación ha sido acogida con beneplácito por la doctrina. Esto debe considerarse en el marco del Derecho de la UE en el que, como ya se ha mencionado, el Tribunal de Justicia ha tenido un papel considerable en suplir las lagunas de un ordenamiento relativamente nuevo. Además, debe entenderse en un momento de marcado declive del estado de derecho en determinados

\footnotetext{
85 Daniel Sarmiento, "Provisional (And Extraordinary) Measures in the Name of the Rule of Law", VerfassungsBlog, 2017/11/24. Disponible en: <https://verfassungsblog.de/provisional-andextraordinary-measures-in-the-name-of-the-rule-of-law/> [Última consulta, 5 de mayo de 2020]. ${ }^{86}$ STJUE de 17 de abril de 2018, Comisión Europea c. República de Polonia, asunto C-441/17, ECLI:EU:C:2018:255.
} 
Estados europeos, ${ }^{87}$ siendo uno de ellos Polonia, ${ }^{88} \mathrm{y}$, en concreto, el socavamiento de la autoridad judicial. ${ }^{89}$

Según Koncewicz, se trata de una decisión que pasará a los anales de la jurisprudencia de la UE, porque demuestra que las violaciones sistémicas requieren respuestas sistémicas y los guardianes del orden legal no deben permitir que el tratado sea abusado por un gobierno corrupto. ${ }^{90}$ Grzeszczak y Muchel consideran que la decisión tomada por el TJUE demuestra que una medida provisional puede ser una herramienta eficiente para la protección de intereses, no solo económicos, sino también sociales, ambientales, culturales y axiológicos. ${ }^{91}$

No obstante, algunos de los autores que alaban el resultado de la decisión consideran que podría haberse redactado de manera más convincente. Por ejemplo, Wennerås argumenta que la conclusión alcanzada por el Tribunal parece defendible, aunque de ninguna manera es una conclusión inevitable. En su opinión, al enfatizar los objetivos y la efectividad del artículo 279 TFUE en lugar de la redacción, y al tratar los argumentos en contra de forma escasa, el TJUE da la impresión innecesaria de crear la ley en lugar de declararla. ${ }^{92} \mathrm{Sin}$ embargo, Prete considera que, si bien el auto puede parecer sorprendente a primera vista, una reflexión sobre el tema debería disipar las dudas sobre la

\footnotetext{
87 Véase Laurent Pech y Kim Lane Schepp "Illiberalism Within: Rule of Law Backsliding in the EU", en Cambridge Yearbook of European Legal Studies, vol. 19, 2017, pp. 3-47.

88 Véase, por parte del TJUE, la STJUE (Gran Sala) de 5 de noviembre de 2019, Comisión Europea c. República de Polonia, asunto C-192/18, EU:C:2019:924; STJUE (Gran Sala) de 24 de junio de 2019, Comisión Europea c. República de Polonia, asunto C-619/18, EU:C:2019:531; y el Auto del Tribunal de Justicia (Gran Sala) de 8 de abril de 2020, Comisión Europea c. República de Polonia, asunto C-791/19 R, ECLI:EU:C:2020:277, éste último una caso muy interesante de aplicación de medidas provisionales. Además, la Comisión Europea decidió poner en marcha en 2018 el mecanismo del artículo 7.1 TUE en relación con Polonia y someter el caso al Consejo de la Unión Europea.

${ }^{89}$ Przemysław Tacik, "Poland's defiance against the CJEU in the Puszcza Białowieska case (C441/17)", en The eurosceptic challenge : national implementation and interpretation of EU law, Hart, Oxford, 2019, pp. 67-86.

90 Tomasz Tadeusz Koncewicz, "The Białowieża case. A Tragedy in Six Acts", VerfassungsBlog, 2018/5/17. Disponible en: <https://verfassungsblog.de/the-bialowieza-case-a-tragedy-in-six-acts/ DOI: <https://dx.doi.org/10.17176/20180518-112614> [Última consulta, 5 de mayo de 2020].

${ }^{91}$ Robert Grzeszczak y Mateusz Muchel, "Provisional Measures Against EU Member States in the light of the Białowieża Forest case.", en Eastern European Journal of Transnational Relations, vol. 2, no 1, 2018, pp. 21-35, p. 33.

92 Pål Wennerås, "Saving a forest and the rule of law: Commission v. Poland", en Common Market Law Review, vol. 56, no 2, 2019, pp. 541-558, p. 541. Disponible en: $<$ https://kluwerlawonline.com/JournalArticle/Common\%20Market\%20Law\%20Review/56.2/2122 $\underline{3}>$ [Última consulta, 5 de mayo de 2020].
} 
solidez de la decisión. Además, cree necesario prestar atención a que el auto tenía que ver con un asunto de suma urgencia por lo que no se le puede exigir que respondiera en detalle todos y cada uno de los argumentos presentados por las partes, y mucho menos que entablara amplias discusiones de naturaleza teórica. Considera que es una decisión que debe ser bienvenida si bien concede que muchas cuestiones relevantes han quedado abiertas. ${ }^{93}$

\section{CONCLUSIONES}

El incumplimiento del Derecho de la UE en materia medioambiental supone serios riegos para la naturaleza, pero también para la seguridad humana, y tiene un coste elevado para los europeos. La Comisión no dispone de recursos para una supervisión general y amplia de los Estados, pero, cuando, a través de denuncias o de oficio, detecta algún tipo de problema sistemático, inicia un procedimiento pre-contencioso de infracción. La mayoría de los mismos se resuelven a través del diálogo, la vía preferida de la Comisión.

No obstante en los casos en los que los Estados siguen recalcitrantemente violando las normas de la UE, se abre la vía del recurso de incumplimiento. La declaración del incumplimiento por parte del TJUE debería ser suficiente para que el Estado prestamente tomará las medidas necesarias para colocarse en línea con el ordenamiento europeo, pero se ha visto que éste no es siempre el caso. Se ha explicado que resultan especialmente problemáticas algunas sentencias en materia medioambiental. Es muy llamativo el dato ya mencionado de que a finales de 2018, 99 procedimientos de infracción seguían abiertos después de un fallo del TJUE porque la Comisión consideraba que los Estados miembros afectados aún no habían cumplido las sentencias y más de la mitad de estos casos estaban relacionados con el medio ambiente.

La Comisión se encuentra ante un dilema, porque instar el recurso del artículo 260.2 podría motivar a los Estados a actuar más rápidamente en parte de los mismos, pero la Comisión usa este mecanismo en muy contadas ocasiones, como se ha visto, con incumplimientos de muy larga duración en los que los Estados no estaban mostrando una auténtica voluntad de avanzar a un ritmo razonable. Básicamente la Comisión usa esta herramienta como la opción

\footnotetext{
${ }^{93}$ Luca Prete, cit., p. 165 y 167.
} 
nuclear, que tiene una utilidad fundamentalmente disuasoria. Puede apreciarse que en algunos casos la Comisión actúa de una manera más política que ejecutiva, porque no quiere ser objeto del rechazo que supondría un constante goteo de multas millonarias a todos los Estados miembros.

Sin embargo, a lo largo de este trabajo se ha visto que algo que sí ha hecho la Comisión, pero sobre todo el Tribunal, ha sido ir desarrollando las herramientas de las que disponen para hacerlas más efectivas y disuasorias. Los dos ejemplos explicados son la acumulación de las multas coercitivas y la suma a tanto alzado en el recurso del artículo 260.2 TFUE y la consideración de que el artículo 279 TFUE cubre la posibilidad de imponer multas coercitivas a los Estados que no respeten las medidas provisionales impuestas.

Ambas son innovaciones procesales muy significativas apoyadas en la necesidad de un cumplimiento homogéneo del Derecho de la UE en todos sus Estados miembros. Estos mecanismos se pueden aplicar a los litigios surgidos en todas las áreas del Derecho de la UE, pero es relevante destacar que el primer caso en el que el Tribunal los ha usado ha sido en ambos en problemas de carácter medioambiental.

Se podría considerar que la razón de esto es la gravedad de los incumplimientos en materia medioambiental, cómo tienden a alargarse en el tiempo, pero a la vez las desastrosas consecuencias que unos pocos meses pueden tener en los ecosistemas, además de las reiteradas reticencias de algunos Estados a cumplir normas medioambientales con más de veinte años de vigencia.

En el caso de las multas coercitivas por no respetar medidas provisionales la mayoría de la doctrina coincide en que hay que entenderlas en el contexto del declive del Estado de Derecho en Polonia como una especie de aviso del tribunal y una herramienta adicional para la Comisión.

A primera vista pueda resultar sorprendente la articulación de un mecanismo de esa naturaleza sin un apoyo explícito en los Tratados, o al menos en alguna de las normas de Derecho derivado, lo que sería prueba de la voluntad de los Estados de darle al Tribunal esa competencia. Esto podría abrir la puerta a que se argumentará que ha actuado ultra vires, es decir, más allá de las competencias que le encomiendan los Tratados. Un riesgo que sin duda es real 
viendo la sentencia del Tribunal Constitucional Federal Alemán de 5 de mayo de 2020 (BVerfG, 2 BvR 859/15). No obstante, el Tribunal ha optado por una interpretación teleológica de la norma que tiene sentido si se incide en la finalidad de las medidas preventivas y la urgencia que las mismas revisten para evitar un mal irremediable.

El caso del bosque de Białowieża era un test-case prácticamente inmejorable porque constituía la tormenta perfecta. Por un lado, es difícil imaginar un caso en el que la urgencia de las medidas sea más clara, cuando se estaban talando árboles de gran valor ecológico en un bosque que puede tardar cientos de años en recuperarse y es probable que el ecosistema haya sufrido daños irreparables. Por otro lado, quedó muy claro que Polonia no respetaba las medidas provisionales, ya que había material gráfico e informes que constataban como la tala y retirada de árboles había continuado a buen ritmo después de la decisión. A esto se sumaba que las autoridades polacas habían mostrado su voluntad de no cumplirlas. Esto es algo muy inusual porque los Estados, incluso cuando no tienen intención de cumplir una decisión del TJUE, normalmente no lo declaran en público.

En cualquier caso, se trata de medidas que son sólo la punta del iceberg de un trabajo mucho más amplio que deben llevar a cabo todos los interesados para mejorar el cumplimiento de las normas europeas de medio ambiente y que idealmente lo mejor sería que no tuvieran que usarse nunca. No obstante, es útil que se hayan añadido a la caja de herramientas con las que cuentan la Comisión y el Tribunal. La Comisión quizás debería en algunos casos ser menos tímida a la hora de usarlos porque en el balance de los intereses en juego sin duda el medio ambiente debe tener un peso muy relevante y, además, el poder de disuasión de un instrumento que casi nunca se usa puede ir difuminándose.

\section{BIBLIOGRAFÍA}

Berendt, Joanna, "Defying E.U. Court, Poland Is Cutting Trees in an Ancient Forest," New York Times, 31/07/2017. Disponible en: $<$ https://www.nytimes.com/2017/07/31/world/europe/poland-bialowieza-forestbison-logging.html > [Última consulta, 5 de mayo de 2020]. 
Börzel, Tanja A. y Buzogány, Aron, "Compliance with EU environmental law. The iceberg is melting", en Environmental Politics, vol. 28, núm. 2, 2019, pp. 315-34. Disponible en: <https://doi.org/10.1080/09644016.2019.1549772> [Última consulta, 5 de mayo de 2020].

Börzel, Tanja A., Environmental Leaders and Laggards in Europe. Why There is (Not) a 'Southern Problem', Routledge, Londres, 2003.

Borzsák, Levente, The Impact of Environmental Concerns on the Public Enforcement Mechanism Under EU Law: Environmental Protection in the 25th Hour, Kluwer Law International B.V., 2011.

Chocrón Giráldez, Ana María, "Proceedings for Interim Measures before the European Court of Justice", en Good Practices in Social Law, 2015, pp. 217-227.

Clément-Wilz, Laure, « Une nouvelle interprétation de l'article 228-2 CE favorisée par le dialogue entre la Cour et son Avocat général », en Cahiers de droit européen, 2005, pp. 725-748.

ClientEarth, Saving Białowieża. Disponible en: $<$ https://www.clientearth.org/saving-bialowieza/> [Última consulta, 5 de mayo de Comisión Europea, Commission Staff Working Document. Annex to the 23rd Annual Report from the Commission on monitoring the application of Community Law (2005) \{com(2006) 416 final\}. Situation in the different sectors, SEC(2006) 999.

Disponible

en:

<https://ec.europa.eu/info/sites/info/files/file import/Situation sectors 2005\%5B SEC\%282006\%29999\%5D en 0.pdf> [Última consulta, 5 de mayo de 2020]. Comisión Europea, Comunicación - Derecho de la UE: mejores resultados gracias a una mejor aplicación (2017/C 18/02). Disponible en: <https://eurlex.europa.eu/legal-

content/ES/ALL/?uri=CELEX\%3A52017XC0119\%2801\%29> [Última consulta, 5 de mayo de 2020].

Comisión Europea, Comunicación al Parlamento Europeo, al Consejo Europeo, al Consejo, al Comité Económico y Social Europeo y al Comité de las Regiones: El Pacto Verde Europeo, COM/2019/640 final. Disponible en: <https://eur- 
lex.europa.eu/legal-content/ES/TXT/?uri=CELEX:52019DC0640> [Última consulta, 5 de mayo de 2020].

Comisión Europea, Comunicación al Parlamento Europeo, al Consejo, al Comité Económico y Social Europeo y al Comité de las Regiones "Revisión de la aplicación de la normativa medioambiental de la UE: problemas comunes y cómo combinar esfuerzos para obtener mejores resultados, $\operatorname{COM}(2017) 63$ final. Disponible en:

$<$ https://eur-lex.europa.eu/legalcontent/ES/ALL/?uri=COM\%3A2017\%3A63\%3AFIN> [Última consulta, 5 de mayo de 2020].

Comisión Europea, Comunicación al Parlamento Europeo, al Consejo, al Comité Económico y Social Europeo y al Comité de las Regiones "Revisión de la aplicación de la normativa medioambiental 2019: Una Europa que protege a sus ciudadanos y mejora su calidad de vida”, COM (2019) 149 final. Disponible en: <https://eur-lex.europa.eu/legal-content/ES/TXT/?uri=COM:2019:0149:FIN> [Última consulta, 5 de mayo de 2020].

Comisión Europea, Comunicación sobre la aplicación del artículo 171 del Tratado CE (96/C 242/07), DOUE C 242 de 21/08/1996, pp. 6-8. Disponible en: $<$ https://eur-

lex.europa.eu/LexUriServ/LexUriServ.do?uri=CELEX:31996Y0821(03):ES:HTM Lᄂ> [Última consulta, 5 de mayo de 2020].

Comisión Europea, Comunicación sobre la aplicación del artículo 228 del Tratado CE (SEC/2005/1658). Disponible en: <https://eur-lex.europa.eu/legalcontent/ES/ALL/?uri=CELEX\%3A52005SC1658> [Última consulta, 5 de mayo de 2020].

Comisión Europea, Comunicación sobre la aplicación del artículo 260, apartado 3, del TFUE (2011/C 12/01), DOUE C 12 de 15.1.2011, pp. 1-5. Disponible en: $<$ https://eur-lex.europa.eu/legal-

content/ES/TXT/?qid=1588847913431\&uri=CELEX:52011XC0115(01)> [Última consulta, 5 de mayo de 2020].

Comisión Europea, Comunicación sobre modificación del método de cálculo de los pagos a tanto alzado y las multas coercitivas diarias propuestos por la Comisión en los procedimientos de infracción ante el Tribunal de Justicia de la 
Unión Europea, C/2019/1396, DOUE C 70 de 25.2.2019, pp. 1-7. Disponible en: $<$ https://eur-lex.europa.eu/legalcontent/ES/TXT/?aid=1588847233764\&uri=CELEX:52019XC0225(01)> [Última consulta, 5 de mayo de 2020].

Comisión Europea, Decimonoveno Informe Anual sobre el control de la aplicación del Derecho comunitario (2001), COM(2002) 324 final. Disponible en: $<$ https://ec.europa.eu/transparency/regdoc/rep/1/2002/ES/1-2002-324-ES-F11.Pdf> [Última consulta, 5 de mayo de 2020].

Comisión Europea, Monitoring the Application of Union Law 2018 Annual Report. Part l: general statistical overview, 2019. Disponible en: $<$ https://ec.europa.eu/info/sites/info/files/report-2018-commission-staff-workingdocument-monitoring-application-eu-law-general-statistical-overviewpart1 0.pdf>_[Última consulta, 5 de mayo de 2020].

Comisión Europea, Monitoring the Application of Union Law 2018 Annual Report. Part II: policy areas, 2019. Disponible en: $<$ https://ec.europa.eu/info/sites/info/files/report-2018-commission-staff-workingdocument-monitoring-application-eu-law-policy-areas-part2.pdf> [Última consulta, 5 de mayo de 2020].

COWI y Eunomia, Study: The costs of not implementing EU environmental law, Comisión Europea, 2019. Disponible en: $<$ https://ec.europa.eu/environment/eir/pdf/study costs not implementing env I aw.pdf> [Última consulta, 5 de mayo de 2020].

Darpö, Jan, "The Commission: A Sheep in Wolf's Clothing?: On Infringement Proceedings as a Legal Device for the Enforcement of EU Law on the Environment, Using Swedish Wolf Management as an Example", en Journal for European Environmental and Planning Law, vol. 13, núm 3, 2016, pp. 270-293. Disponible en: $<$ https://doi.org/10.1163/18760104-01303004> [Última consulta, 5 de mayo de 2020].

DG Environment, Management Plan 2013, Ref. Ares(2013)41606. Disponible en: <https://ec.europa.eu/dgs/environment/pdf/management plan 2013.pdf> [Última consulta, 5 de mayo de 2020]. 
Fajardo del Castillo, Teresa, "Primera multa coercitiva a España en aplicación del procedimiento del artículo 228.2 del Tratado CE: comentario a la sentencia del TJCE de 25 de noviembre de 2003, Comisión c. España, as. C-278/01", en Revista General de Derecho Europeo, №. 4, 2004.

Falkner, Gerda "A causal loop? The Commission's new enforcement approach in the context of non-compliance with EU law even after CJEU judgments", en Journal of European Integration, vol. 40, núm. 6, 2018, pp. 769-784. Disponible en: $\quad<$ https://www.tandfonline.com/doi/full/10.1080/07036337.2018.1500565> [Última consulta, 5 de mayo de 2020].

Falkner, Gerda, "Fines against member states: An effective new tool in EU infringement proceedings?", en Comparative European Politics, vol. 14, 2016, pp. 36-52. Disponible en: <https://doi.org/10.1057/cep.2015.8> [Última consulta, 5 de mayo de 2020].

Giménez Sánchez, Itziar, y Robles Garzón, Juan Antonio, La eficacia de las sentencias dictadas por el TJCE, Aranzadi, Pamplona, 2003.

Grohs, Sibylle, "Article 258/260 TFEU Infringement Procedures: The Commission Perspective in Environmental Cases", en Compliance and the Enforcement of EU Law, Marise Cremona (ed.), Oxford University Press, 2012, pp. 57-73.

Grzeszczak, Robert y Muchel, Mateusz, "Provisional Measures Against EU Member States in the light of the Białowieża Forest case.", en Eastern European Journal of Transnational Relations, vol. 2, no 1, 2018, pp. 21-35.

Hedemann-Robinson, Martin, Enforcement of European Union Environmental Law: Legal Issues and Challenges, Routledge, 2015 (2ª Edición), pp. 136-137.

Hofmann, Andreas, "Left to interest groups? On the prospects for enforcing environmental law in the European Union", en Environmental Politics, vol. 28, 2019, pp. 342-364, <https://doi.org/10.1080/09644016.2019.1549778> [Última consulta, 5 de mayo de 2020].

Horspool, Margot y Humphreys, Matthew, European Union Law, Oxford University Press, 2012.

Institute for European Environmental Policy, Closing the gap: implementing European environmental policies, 2019. Disponible en: 
$<$ https://ieep.eu/uploads/articles/attachments/a41d4af7-fb05-4a7f-8ddf8d6b077f828d/Closing\%20the\%20gap\%20-\%20final.pdf?v=63727460550> [Última consulta, 5 de mayo de 2020]. Jack, Brian, "Article 260(2) TFEU: An Effective Judicial Procedure for the Enforcement of Judgements?", en European Law Journal, vol. 19, núm. 3, 2013, pp. 404-421. Disponible en: <https://doi.org/10.1111/eulj.12030> [Última consulta, 5 de mayo de 2020].

Jacobs, Francis, "The role of the European Court of Justice in the protection of the environment", en Journal of Environmental Law, vol. 18, núm. 2, 2006, pp. 185-205. Doi: 10.1093/jel/eql012 [Última consulta, 5 de mayo de 2020].

Jordan, Andrew, "The Implementation of EU Environmental Policy; A Policy Problem without a Political Solution?", en Environment and Planning: Government and Policy, vol. 17, núm. 1, pp. 69-90. Disponible en: <https://doi.org/10.1068/c170069> [Última consulta, 5 de mayo de 2020].

Kilbey, lan, "Financial penalties under Article 228(2) EC: Excessive complexity?", en Common Market Law Review, vol. 44, núm. 3, 2007, pp. 743-759, p. 749. Disponible

en: $<$ https://kluwerlawonline.com/JournalArticle/Common\%20Market\%20Law\%20R eview/44.3/5253> [Última consulta, 5 de mayo de 2020].

Koncewicz, Tomasz Tadeusz, "The Białowieża case. A Tragedy in Six Acts", VerfassungsBlog, 2018/5/17. Disponible en: <https://verfassungsblog.de/thebialowieza-case-a-tragedy-in-six-acts/

DOI: $<$ https://dx.doi.org/10.17176/20180518-112614> [Última consulta, 5 de mayo de 2020].

Krämer, Ludwig, Environmental judgements by the Court of Justice and their duration, Research Papers in Law/Cahiers juridiques No 4/2008, College of Europe, 2008.

Mikusińskiab, Grzegorz; Witold Bubnickic, Jakub; Churskic, Marcin; Czeszczewikd, Dorota; Walankiewiczd, Wiesław; y Kuijperc, Dries P. J., "Is the impact of loggings in the last primeval lowland forest in Europe underestimated? The conservation issues of Białowieża Forest", en Biological Conservation, vol. 227 , 2018 , pp. 266-274. Disponible: 
$<$ https://doi.org/10.1016/i.biocon.2018.09.001> [Última consulta, 5 de mayo de 2020].

Moreiro González, Carlos, "A propósito de la Sentencia del Tribunal de Justicia de 4 de julio de 2000 en el asunto C-387/97, Comisión CE, apoyada por Reino Unido contra Grecia", en Gaceta Jurídica, № 208, 2000, pp. 87-95.

Naim-Gesbert, Eric, "De la toujours chaotique transposition de la directive 91/271/CEE (eaux urbaines résiduaires) : note sur CJUE 25 juillet 2018, Commission c/Espagne, aff C-205/17 ", en Revue Juridique de l'Environnement, vol. 43, núm. 4, 2018, pp. 848-851.

Pech, Laurent y Schepp, Kim Lane "Illiberalism Within: Rule of Law Backsliding in the EU", en Cambridge Yearbook of European Legal Studies, vol. 19, 2017, pp. 3-47.

Peers, Steve, "Sanctions for Infringement of EU Law after the Treaty of Lisbon", en European Public Law, vol. 18 (2012), pp. 33-64.

Prete, Luca, "Can't See the Forest for the Trees? Penalties Under Article 279 TFEU", en Yearbook on Procedural Law of the Court of Justice of the European Union-2019, MPILux Research Paper, 2020, pp. 157-170. Disponible en: $<$ http://dx.doi.org/10.2139/ssrn.3530773> [Última consulta, 5 de mayo de 2020].

Rigaux, Anne, « Manquement sur manquement: propositions inédites de l'Avocat général sur les conséquences financières potentielles des manquements persistants et structurels », en Europe 2004 Juin Chron, núm. 4, pp. 4-5.

María Isabel Rodríguez Valero, Administrative procedure in environment files linked with Article 258 TFEU proceedings: a lawyer's perspective, Parlamento Europeo, 2010.2 Disponible en: <https://www.europarl.europa.eu/RegData/etudes/note/join/2011/432753/IPOLJURI NT(2011)432753 EN.pdf> [Última consulta, 5 de mayo de 2020].

Sáenz de Santamaría, Paz Andrés, "Primera multa coercitiva a un estado miembro por inejecución de sentencia. (Comentario a la STJCE de 4 de julio de 2000, Comisión c. Grecia)", en Revista de Derecho Comunitario Europeo, ํo 8 , 2000, pp. 493-518. 
Sarmiento, Daniel, "Interim Revolutions", Verfassungsblog, 22/10/2018. Disponible en: <https://verfassungsblog.de/interim-revolutions/> [Última consulta, 5 de mayo de 2020].

Sarmiento, Daniel, "Provisional (And Extraordinary) Measures in the Name of the Rule of Law", VerfassungsBlog, 2017/11/24. Disponible en: $<$ https://verfassungsblog.de/provisional-and-extraordinary-measures-in-thename-of-the-rule-of-law/> [Última consulta, 5 de mayo de 2020].

Sobrido-Prieto, Marta, "Primera condena al pago simultáneo de una multa coercitiva y de una suma a tanto alzado por inejecución de sentencia: comentario a la Sentencia del Tribunal de Justicia de las Comunidades Europeas de 12 de julio de 2005, C-304/02, Comisión / Francia", en Revista General de Derecho Europeo, №. 9, 2006.

Tacik, Przemysław, "Poland's defiance against the CJEU in the Puszcza Białowieska case (C-441/17)", en The eurosceptic challenge: national implementation and interpretation of EU law, Hart, Oxford, 2019, pp. 67-86.

Tribunal de Justicia de la Unión Europea, Informe anual 2018. Panorámica del año, $2019 . \quad$ Disponible en: $<$ https://curia.europa.eu/jcms/upload/docs/application/pdf/201906/20190650 ra pan es 2019-06-06 09-48-20 48.pdf> [Última consulta, 5 de mayo de 2020].

Volcansek, Mary L., "The European Court of Justice: Supranational policymaking", en West European Politics, vol. 15, núm. 1992, 2007, pp. 109-121. Disponible en: <https://doi.org/10.1080/01402389208424924> [Última consulta, 5 de mayo de 2020].

Wennerås, Pål, "A new dawn for Commission enforcement under Articles 226 and 228 EC: General and persistent (gap) infringements, lump sums and penalty payments", en Common Market Law Review, vol. 43, núm. 1, 2006, pp. 31-62. Disponible en: <https://kluwerlawonline.com/JournalArticle/Common\%20Market\%20Law\%20R eview/43.1/4072> [Última consulta, 5 de mayo de 2020].

Wennerås, Pål, "Making effective use of Article 260 TFEU", en András Jakab y Dimitry Kochenov (eds.), The Enforcement of EU Law and Values, Oxford 
University Press, 2017, pp. 79-111, DOI:10.1093/acprof:oso/9780198746560.003.0006.

Wennerås, Pål, "Sanctions against Member States under Article 260 TFEU: alive, but not kicking?", en Common Market Law Review, vol. 49, núm. 1, 2012, pp. 145-175.

Wennerås, Pål, "Saving a forest and the rule of law: Commission v. Poland", en Common Market Law Review, vol. 56, n² 2, 2019, pp. 541-558. Disponible en: $<$ https://kluwerlawonline.com/JournalArticle/Common\%20Market\%20Law\%20R eview/56.2/21223> [Última consulta, 5 de mayo de 2020]. 